NBER WORKING PAPER SERIES

\title{
PROGRAM RECERTIFICATION COSTS: EVIDENCE FROM SNAP
}

\author{
Tatiana Homonoff \\ Jason Somerville \\ Working Paper 27311 \\ http://www.nber.org/papers/w27311 \\ NATIONAL BUREAU OF ECONOMIC RESEARCH \\ 1050 Massachusetts Avenue \\ Cambridge, MA 02138 \\ June 2020
}

We gratefully acknowledge Manasi Deshpande, Peter Ganong, Jacob Goldin, Colin Gray, Doug Miller, Matt Notowidigdo, Ted O'Donoghue, Zhuan Pei, and Matt Unrath as well as conference and seminar participants at UC-Berkeley, Yale, Vanderbilt, Georgia State, UVA-Batten, HunterCUNY, NYU, Cornell, NBER-Public Economics, IRP-SRW, AEA, APPAM, and UPenn-CHIBE for conversations and suggestions that have greatly improved the quality of this project. We especially thank Peri Weisberg for providing data and guidance on policies and practices along with Mark Woo, Noelle Simmons, Dan Kelly, Taninha Ferreira, Yakob Kflom, Priscilla Prado, James Choi, Alan Geist at the San Francisco Human Services Agency and the California Department of Social Services as well as Nate Higgins and Rurui Kuang from the Social and Behavioral Sciences Team. All remaining errors are our own. The views expressed herein are those of the authors and do not necessarily reflect the views of the National Bureau of Economic Research.

NBER working papers are circulated for discussion and comment purposes. They have not been peer-reviewed or been subject to the review by the NBER Board of Directors that accompanies official NBER publications.

(C) 2020 by Tatiana Homonoff and Jason Somerville. All rights reserved. Short sections of text, not to exceed two paragraphs, may be quoted without explicit permission provided that full credit, including $\odot$ notice, is given to the source. 
Program Recertification Costs: Evidence from SNAP

Tatiana Homonoff and Jason Somerville

NBER Working Paper No. 27311

June 2020

JEL No. H53,I14,I38

\begin{abstract}
$\underline{\text { ABSTRACT }}$
Recipients of means-tested program benefits must periodically document continued eligibility through a recertification process. We find evidence that the administrative burden associated with SNAP recertification leads to decreases in program participation. Cases assigned to later recertification interview dates, which leave less time to reschedule missed interviews, are over 20 percent less likely to recertify than cases assigned to interviews earlier in the month. Cases that fail recertification due to later assignments lose an average of $\$ 600$ in benefits in the following year. These losses are highly skewed: many cases quickly re-enroll, while one quarter remain off SNAP for over a year post-recertification.
\end{abstract}

\author{
Tatiana Homonoff \\ New York University \\ Robert F. Wagner School of Public Service \\ 295 Lafayette Street, 2nd Floor \\ New York, NY 10012 \\ and NBER \\ tatiana.homonoff@nyu.edu \\ Jason Somerville \\ Cornell University \\ Department of Economics \\ Uris Hall, Room 457 \\ Ithaca, NY 14853 \\ js2946@cornell.edu
}


Researchers have documented incomplete take-up across a wide variety of social programs, often citing under-awareness of program availability, unfamiliarity with eligibility rules, or other application costs as barriers to take-up (Madrian and Shea, 2001; Chetty, Friedman and Saez, 2013; Bhargava and Manoli, 2015; Finkelstein and Notowidigdo, 2019). ${ }^{1}$ In addition to these initial costs of enrollment, recipients of means-tested program benefits must document continued eligibility through a periodic recertification process. For example, the Supplemental Nutrition Assistance Program (SNAP) requires that recipients submit income verification and complete a caseworker interview at least once per year to maintain program access. Cases that miss the recertification deadline by even one day are terminated from the program.

A substantial fraction of cases fail to recertify for SNAP - in San Francisco, for example, over half of active SNAP cases fail recertification. One possible explanation for this finding is that the majority of cases are no longer eligible, underlining the importance of the recertification process in ensuring program integrity. However, half of these recertification failures re-enter the program within the following months, many within less than a month, evidence consistent with the possibility that many cases fail recertification due to administrative burden associated with the recertification process rather than due to ineligibility.

This paper examines the effect of one of the components of the recertification process - the timing of the recertification interview assignment - to determine its effect on recertification success and subsequent program participation. To successfully recertify for SNAP, recipients must complete a recertification interview by the end of the calendar month in which their certification period ends. In San Francisco, program administrators assign each case an initial interview date that is included in an appointment letter in their recertification packet. Specifically, these initial interview dates are randomly assigned across cases and staggered throughout the month to smooth caseworker workloads. Recipients may resched-

\footnotetext{
${ }^{1} \mathrm{~A}$ related literature in the field of public administration demonstrates several instances in which administrative burden, conceptualized as a combination of learning, psychological, and compliance costs associated with interactions with government programs, impacts program participation (Heinrich, 2015; Herd and Moynihan, 2019).
} 
ule their interview for any point during the month, however, all recipients must complete the recertification process by the end of the calendar month regardless of the timing of the initial interview assignment. This means that recipients who are assigned a date at the start of the calendar month have more than four weeks to complete their recertification requirements post-interview assignment (such as rescheduling a missed interview or compiling income documentation), while others have as little as a few days.

To estimate the effect of interview assignment, we analyze unique administrative data from the San Francisco Human Services Agency (SF-HSA) on the universe of the county's roughly 40,000 SNAP recertification cases from November 2014 to November 2016. The data contain information on recertification date, both initial and rescheduled interviews, recertification outcome, and subsequent reapplications for cases that fail to recertify. This data allows us to examine how the timing of the administrative process affects both recertification and subsequent participation by comparing outcomes for those who were randomly assigned to early versus late initial interview dates.

We find that the initial interview assignment has a large and significant impact on recertification success: a case assigned to an interview at the end of the recertification month is 11 percentage points less likely to recertify than a case assigned to an interview at the start of the month, a 22 percent decrease. We find evidence that suggests that administrative burden associated with the recertification process not only decreases recertification success, but longer-term program participation as well. Specifically. we find that cases with interview assignments at the end of the month are 3 percentage points less likely to participate in SNAP at any point in the year following recertification. We estimate that the marginal case that fails recertification due to later interview assignment loses an average of almost $\$ 600$ in SNAP benefits in the year following recertification.

Estimates of average benefit losses mask substantial heterogeneity across these marginal recertification failures: 25 percent of cases that fail recertification due to later interview assignment remain off the program for at least one full year post-recertification, while the 
remaining 75 percent of cases re-enter the program shortly after being discontinued. This suggests that while the majority of cases may miss as little as a week of benefits, a quarter of these marginal failures lose over a year of benefits (up to roughly $\$ 2,000$ per person). However, program churn, recertification failure followed by subsequent re-enrollment, is not without its own costs: administrative expenses associated with cases that churn are up to twice as large as for cases that successfully recertify (Mills et al., 2014). This highlights important differences in the distribution of costs associated with recertification failure depending on the post-recertification outcome. Cases that remain off the program long-term suffer large private costs in the form of missed benefits, but create no additional costs to program administrators. In contrast, cases that churn experience smaller private costs, but generate large administrative costs.

We provide evidence to suggest that under-awareness, coupled with difficulty in rescheduling missed appointments, may explain a substantial portion of the relationship between interview assignment and recertification. We find that cases with later interview assignments, which have less time to reschedule a missed appointment before the recertification deadline, are 7 percentage points less likely to complete an interview. However, we find no relationship between interview assignment and completion of the first attempted interview, suggesting that some cases may be inattentive to or unaware of their interview assignment. Consistent with this interpretation, we find evidence that additional early alerts (such as missed interview voicemails or text communications) may partially mitigate the negative effects of late interviews. These findings suggest that improved communication strategies on the part of program administrators may prevent eligible cases from losing program access.

Our results contribute to a growing literature detailing instances in which administrative hassles lead to low rates of initial program enrollment. Several recent interventions demonstrate that informing likely eligible individuals about program availability leads to significant increases in enrollment (Armour, 2018; Barr and Turner, 2018; Bhargava and Manoli, 2015). Other work shows that automatic enrollment, pre-population of application 
forms, and other types of application assistance lead to higher enrollment across a variety of programs (Madrian and Shea, 2001; Bettinger et al., 2012; Finkelstein and Notowidigdo, 2019). Conversely, increased application costs associated with local program office closures lead to significant decreases in program applications (Rossin-Slater, 2013; Deshpande and $\mathrm{Li}, 2019)$.

The requirements associated with initial application and recertification are often quite similar, however, there are several reasons to believe that barriers to program participation differ across the two stages. First, awareness of a program's availability is a key issue for program enrollment, but not for recertification. Second, individuals who have already applied for a program at least once are likely to have a better understanding of their eligibility than first time enrollees. Lastly, current participants have demonstrated a past preference for participation, while eligible but unenrolled individuals may have purposely chosen not to participate in the program for a variety of reasons such as stigma (Moffitt, 1983; Currie and Grogger, 2001). Our findings contribute to a small, but growing literature on program recertification that shows that reminders (Castleman and Page, 2016) and flexibility in the recertification process, such as phone interviews or online case management (Ganong and Liebman, 2018; Gray, 2019), can lead to higher rates of participation. ${ }^{2}$

Our results also contribute to a literature examining the relationship between hassle costs associated with program participation and targeting efficiency. While standard models suggest that application costs improve targeting efficiency (Nichols and Zeckhauser, 1982), alternative models suggest that these costs can worsen targeting efficiency (Deshpande and $\mathrm{Li}, 2019)$. We estimate the effect of interview assignment on recertification and program participation by benefit level and find results consistent with a model in which administrative burden in the form of later interview assignments worsens targeting efficiency. These findings are in line with several prior empirical findings on heterogeneity in response to barriers to

\footnotetext{
${ }^{2} \mathrm{~A}$ related literature shows that shorter certification periods are associated with lower SNAP enrollment (Currie and Grogger, 2001; Kabbani and Wilde, 2003; Ribar, Edelhoch and Liu, 2008; Ganong and Liebman, 2018). In a slightly different context, Hastings and Shapiro (2018) use these certification periods as an exogenous source of variation in timing of exit from the SNAP program.
} 
program take-up (Currie and Grogger, 2001; Bhargava and Manoli, 2015; Deshpande and Li, 2019), while standing in contrast to others (Alatas et al., 2016; Finkelstein and Notowidigdo, 2019).

This paper is organized as follows. Section I reviews the institutional background on SNAP recertification. Section II describes the recertification and interview assignment process. Section III describes the data sources used in the empirical analysis. Section IV presents descriptive statistics. Section V estimates of the impact of initial interview date assignment on recertification and program participation. Section VI describes the welfare implications. Section VII discusses possible mechanisms. Section VIII examines the effect on targeting efficiency. Section IX concludes.

\section{Institutional Background}

The Supplemental Nutrition Assistance Program (SNAP) is the largest nutritional assistance program in the United States, serving over 42 million individuals at an annual cost of $\$ 69$ billion (CBO, 2018). The program provides monthly food vouchers to low-income households via Electronic Benefits Transfer (EBT) cards with an average monthly benefit of $\$ 126$ per person. The program is federally funded but administered by the states who are responsible for determining eligibility and distributing benefits.

SNAP is a means-tested program meaning that all recipients are subject to income eligibility requirements determined by the state. ${ }^{3}$ To ensure that individuals receiving SNAP are eligible for program benefits, recipients must complete a recertification process at the end of each certification period. Certification periods are typically between six and twelve months

\footnotetext{
${ }^{3}$ In California, for example, eligibility requirements are based on two income tests: gross household income must be below $200 \%$ of the federal poverty line (FPL) and net income must be below $100 \%$ FPL. However, many households are only subject to the gross income test including those with only 1-2 members (85 percent of our sample) or recipients of other means-tested programs such as Temporary Assistance for Needy Families (TANF). Additionally, individuals between the ages of 18 to 49 who are unemployed but not disabled and who do not have any dependent children (Able-Bodied Adults Without Dependents or ABAWDs), are limited to three months of eligibility in any given 36 -month period or subject to work requirements. Importantly for this paper, all counties in California operated under a waiver of the ABAWD work requirements for the duration of our study period.
} 
long, though the exact length varies by state and household composition. ${ }^{4}$

To successfully recertify, cases must complete the following three steps in any order by the end of the certification period. First, cases must fill out and submit a recertification application. This form elicits detailed information on household composition, income, and expenses to determine eligibility and benefit amount. Second, cases must submit documents (e.g., pay stubs) to verify income and other household circumstances described in the recertification application. Finally, cases must complete a scheduled interview with a SNAP caseworker, either in-person or over the phone. These interviews do not entail a determination of eligibility, but rather are intended to assist the recipient with the recertification process, for example, by clarifying documents required for income verification or helping to complete the recertification forms. At the same time, completion of a caseworker interview at least once every 12 months is a federal requirement for SNAP recertification - eligible cases that do not complete the interview cannot successfully recertify.

Cases that fail recertification, either due to ineligibility or by not completing one of the steps of the recertification process, are terminated from the program at the end of the certification period. Discontinued cases may reapply for the program by initiating a new application (rather than the streamlined recertification process). Importantly, enrollment is not retroactive for these cases: benefits are prorated from the time the case is discontinued until the date that the new application is successfully processed and may be received with a delay. This suggests that even short exit spells could result in substantial benefit losses; for example, a household of four could lose up to $\$ 150$ in benefits in just one week.

\section{CalFresh Recertification and Interview Assignment Process}

CalFresh, California's SNAP program, served over two million households at an annual cost of seven billion dollars in 2016. California has one of the lowest SNAP take-up rates in the

\footnotetext{
${ }^{4}$ For example, households in which all residents are either elderly or disabled may receive a longer certification period of up to 24 months, though the state agency must have contact with the household at least once every twelve months. Conversely, households determined to be likely to become ineligible in the near future may be assigned to certification periods as short as one month.
} 
country at 72 percent (Cunnyngham, 2019) while at the same time, California is the second most administratively costly SNAP agency in the country. Annual certification-related state administrative expenses, which account for 76 percent of all expenses nationally, are over $\$ 600$ per case in California, more than twice the national average (Geller and Isaacs, 2019).

The majority of CalFresh recipients must recertify for the program every twelve months. ${ }^{5}$ To understand the timing of the recertification process, consider a case whose certification period ends in June 2016. All certification periods end on the last day of the calendar month, so in our example, recertification must be completed by June 30,2016 . The recertification process begins with a Notice of Expiration of Certification which is generated and sent to all cases 45 days before the end of the certification period, on May 15, 2016 in our example. This notice alerts cases that the end of their certification period is approaching, briefly details the recertification process, and informs them that they will be receiving a detailed recertification packet and interview assignment in the mail (See Appendix Figure 1 for an example of this form and other forms used in the recertification process). Cases that have opted in to receive text updates, roughly one quarter of all cases in our sample, also receive a communication within the next few days informing them that their certification period is ending.

Case workers then assign each case an initial interview date to take place within the first four weeks of June. Around the third week of May, case workers send out the Recertification, Reauthorization, and Renewal (RRR) packets. ${ }^{6}$ These packets contain the recertification form (CF-37), an interview appointment letter, and several other unrelated forms such as voter registration forms. Cases are asked provide detailed information on the income and expenses for all household members, along with income verification, for the calendar month prior to the end of the certification period (May 2016 in our example).

\footnotetext{
${ }^{5}$ Additionally, most households in California must complete a shorter semi-annual report called the SAR-7. Unlike the annual recertification, this interim reporting requirement does not include a caseworker interview, hence we focus only on annual recertification cases in this paper.

${ }^{6}$ The vast majority of packets are sent within the week following the Notice of Expiration of Certification. While the range of possible send dates is not large, we find that cases with interview assignments received their packet an average of 2.5 days earlier than those with later dates (see Appendix Figure 2 for a distribution of sent dates for cases with early versus late interviews). We address this in Section V.
} 
The appointment letter contains information on the initial interview date assignment and the interview time. Cases that provided a phone number on the initial application or subsequent case updates are assigned phone interviews; all other cases are assigned an inperson interview at the local SNAP office. ${ }^{7}$ The letter also provides information on how to reschedule the interview if the recipient has a conflict. Recipients may reschedule their interview or complete an on-demand walk-in interview at the SNAP offices at any time during the recertification month. If a recipient misses the scheduled interview, the case receives a notice of missed interview and, if a phone number was provided, a voicemail instructing them to contact a case worker to reschedule their interview. All cases that place a request to reschedule before the end of the certification period are granted a new interview, even on the last day of the recertification month.

In San Francisco, the county in which our study takes place, program administrators assign interviews throughout the recertification month, staggering them to smooth caseworker workload. The interview assignment process is as follows. Caseworkers are given the full list of cases whose certification period ends in the following month. These cases are grouped by case language and appointment type (phone or in-person). Cases are sorted within group by Case ID number and, subsequently, the list of available interview dates is repeatedly appended to the case list until all cases are assigned an initial interview date. ${ }^{8}$ For example, if there are 20 possible interview dates for Spanish language phone interviews in the month of June 2016, cases 1, 21, and 41 would be assigned to the first interview date, cases 2,22 , and 42 would be assigned to the second interview date, and so on. As a result, this assignment process produces as-good-as-random assignment of each case to its initial interview date conditional on month by case language by interview type (the "assignment group").

\footnotetext{
${ }^{7}$ The San Francisco SNAP office offers interviews in six languages: English, Spanish, Chinese (Cantonese and Mandarin), Vietnamese, Tagalog, and Russian. Unsupported languages are served by staff without multilingual skills, using external translation services.

${ }^{8}$ The list of available interview dates excludes weekends, holidays, and the last two days of the calendar month with fewer interviews scheduled on the first day of the month to address increased call volumes associated with discontinuation of benefits. In-person interviews do not meet on Fridays. Lastly, the list adjusts for non-major language (Vietnamese, Tagalog, and Russian) caseworker availability.
} 
Figure 1 presents a graph of the distribution of initial interview dates for the recertification cases in our study population (described in Section III). The distribution is approximately uniform across the first three weeks of the month with fewer interviews scheduled after the 23rd of the month. This is largely due to the fact that interviews were not scheduled after the 24th during the first few months of our study period, but also partly due to a larger number of holidays falling at the end of the calendar month.

Regardless of when a case's initial interview is scheduled, all cases must complete the recertification process by the last day of the calendar month of their certification period. While interviews can be rescheduled for any time within the recertification month, only 6 percent of cases reschedule their interview prior to the randomly assigned interview date. Therefore, most cases that are assigned an initial interview date at the beginning of the month have over four weeks post-interview to complete the process - for example, to reschedule a missed interview, fix errors in the recertification application, or gather valid income verification while cases that are assigned an interview at the end of the month may only have a few days.

\section{Data}

Our data contain the universe of SNAP cases in San Francisco County scheduled for recertification between November 2014 and November 2016 provided by the San Francisco Human Services Agency (SF-HSA). ${ }^{9}$ The data include the case's recertification month, the date the recertification packet was sent, and an indicator for whether the case recertified or was discontinued from the program. We then combine this data with information on all interviews scheduled with the SNAP office, including interviews assigned by the SNAP office as well as interviews that were rescheduled by the program participant. Importantly, the data also include the date on which the appointment was created, allowing us to determine the initially assigned interview date. The data include the date and time of all scheduled

\footnotetext{
${ }^{9}$ We focus on cases that are current SNAP recipients but that are not currently receiving TANF, as the recertification interview assignment process differs for those cases in order to better align the recertification process for the two programs.
} 
interviews and whether the interview was successfully completed. We also obtain data on all walk-in appointments, as cases can complete an on-demand interview by visiting a SNAP office. Records on the submission of recertification forms and verification documents, such as income verification documents were not available.

We exclude recertification cases that were inconsistent with administrative guidelines for scheduling interviews. First, we exclude cases that were sent a recertification packet but were not assigned a caseworker interview. ${ }^{10}$ Next, we drop cases in which the first interview was assigned in the recertification month or before the 13 th of the month prior to the recertification month as these interviews are typically scheduled around the 15 th of the month prior to recertification and deviations from this schedule suggest that the interview assignment may not have followed the typical assignment process; for similar reasons, we also exclude the small number of cases whose interviews were scheduled to take place less than seven days after the recertification packets were sent.

We make two additional sample restrictions. Caseworkers are matched to recipients based on their ability to conduct interviews in the recipient's language. While the interview assignment process for cases speaking non-major languages (Russian, Tagalog, and Vietnamese) generally follows the process described in Section II, assignment is constrained by the availability of staff who speak these languages. As a result, we drop the roughly 3 percent of cases that were conducted in one of the three non-major case languages. Finally, conversations with staff suggest that caseworkers experience particularly heavy call volumes on the first day the calendar month, the day on which benefits to recipients who fail recertification are discontinued. To avoid potential interactions with increased workload on this date, we exclude cases assigned to interview dates on the first of the month, though our results are robust to including these cases. This leaves us with a final sample of 39,702 recertification events across 30,420 unique cases.

\footnotetext{
${ }^{10}$ The majority of these (roughly 1,800) cases occurred during the first six months of our sample period during a time when recertification interviews were waived for cases in which all adults are elderly or disabled without income.
} 
To examine the effect of initial interview assignment on post-recertification outcomes, we merge our sample to data on all subsequent SNAP applications through October 2017. This data allows us to follow the recertification cases in our sample for a year after the end of their certification period. From this data, we are able to determine whether a case that failed recertification rejoined the program within the following months (i.e., churned), or if the recertification process resulted in a longer-term discontinuance from the program.

We then link identifiers for all individuals associated with a recertification case to administrative data from the Employment Development Department (EDD). These data contain individual wage earnings in each quarter provided by employers for all individuals associated with a case for a year after the end of the certification period. While caseworkers have access to this data source, the data is provided with a lag and so EDD data is not used as part of the recertification process to assess eligibility.

The data also include detailed demographic information on the case and the head of household. These data include information that is required as part of the initial SNAP application process, such as household size and composition, and is updated through prior recertifications or semi-annual reporting. The data also contain information from administrative sources on each case's SNAP participation history including the case's initial enrollment date and the monthly benefit amount at the time of recertification. Lastly, the data include information about the head of household including date of birth, gender, ethnicity, and citizenship status.

Finally, we collected data on receipt of text communications sent to cases that opted in to this voluntary program. These communications were used throughout our study period, however, San Francisco only began collecting individual-level data on receipt of texts for cases due for recertification in October 2015 and after. As a result, all analyses involving these data are restricted to this time period. 


\section{Descriptive Statistics}

\section{A. Demographics and Randomization Checks}

Table 1 presents summary statistics of the demographic characteristics of SNAP participants. Since our study focuses on the county of San Francisco - a large, urban city - we present these summary statistics for a nationally representative sample of SNAP recipients using data from the USDA's SNAP Quality Control System (column 1) as well as for our study population (column 2). A few characteristics of our sample are worth comparing to this nationally representative population. First, the average size of the households in our population is somewhat smaller than the average SNAP household with just under one third of households in our sample reporting at least one child compared to 40 percent of SNAP households nationwide. San Francisco SNAP households are more likely to receive the maximum SNAP benefit (63 versus 39 percent), more likely to be receiving wage earnings (34 versus 28 percent), more racially diverse (79 versus 54 percent non-white), less likely to have a female head of household (46 versus 68 percent), and less likely to be headed by a US citizen (77 versus 85 percent) than SNAP households nationwide.

Columns 3 and 4 present demographic characteristics of our sample separately for cases with early initial interview dates (before the 14th of the month) versus late interview dates (between the 14th and 29th of the month). The average demographic make-up of cases initially assigned to early versus later interview dates are quite similar. Column 5 presents results from a test for equality of means between these groups. Differences for most characteristics are small and not statistically significant, suggesting that interview date assignment was not correlated with observed case demographics. We do observe small but statistically significant differences in citizenship for those assigned early versus late interview assignments. We explore the sensitivity of our results to the inclusion of these controls in the following section. 


\section{B. Recertification Outcomes}

Table 2 presents summary statistics on various outcomes related to the recertification process. Just over three quarters of our sample completed a caseworker interview. For the majority of cases, the completed interview was the first attempted interview, i.e., the initially assigned interview or, for the small fraction of cases that called to reschedule prior to the initially assigned date, the reassigned interview date. It is important to note again that interview completion does not include a determination of eligibility - in other words, interview completion is necessary to complete recertification, but it is not sufficient. Overall, we find that 48 percent of cases successfully recertified.

That over half of all cases fail recertification highlights the potential importance of the recertification process itself: if a substantial fraction of SNAP recipients have not maintained eligibility for the program over time, periodic eligibility verification ensures program integrity and contains the costs of the program. However, we provide evidence that a substantial proportion of cases that fail recertification appear to have failed in spite of maintaining eligibility.

First, over half of cases that fail recertification successfully reapply for SNAP within the subsequent months, yielding a 90-day churn rate of 46 percent. In other words, roughly one quarter of the cases in our sample failed recertification and were discontinued from the program, but were deemed eligible within the following months. These estimates are consistent with, but somewhat larger than estimates from a recent USDA report on SNAP churn (Mills et al., 2014). Figure 2 shows that 78 percent of cases that churn within 90 days of recertification do so within the first month, many within the first week. It is certainly possible that short-term income fluctuations may lead to this month-to-month pattern of SNAP eligibility. However, our data point to a potentially more plausible story: cases remained eligible, but failed recertification due to procedural issues such as failing to complete a caseworker interview or submit income verification by the recertification deadline.

Second, we use quarterly administrative wage earnings data to directly estimate the 
eligibility of recertification cases in our sample. Table 3 presents the fraction of recertification cases with wage earnings below the gross income limit for SNAP eligibility in California (200 percent FPL) as well as the proportion of cases with no wage earnings at all. We provide these estimates for the full sample as well as by post-recertification outcome: those that recertified, churned (both before and after 90 days), and those that remained off the program for at least 12 months after failing recertification. Figure 3 plots the average quarterly earnings in the recertification quarter and the four quarters post-recertification for the same groups.

We find that estimated eligibility for cases that recertified and those that churned within 90 days are very similar - 97 percent of cases that recertify have average monthly wage earnings below the gross income limit in the quarter of recertification versus 96 percent for cases that churn. Similarly, the fraction of cases with no wage earnings in the recertification quarter are 69 percent among cases that recertify and 68 percent for cases that churn. Figure 3 tells a similar story: the average wage earnings of cases that recertify and cases that churn within 90 days are nearly identical in all quarters. Average quarterly earnings estimates are roughly twice as high for longer-term discontinued cases; nonetheless, we estimate that 85 percent of cases that remain off the program for a full year have average quarterly wage earnings below the SNAP gross income limit during the recertification quarter and 58 percent have no wage earnings at all.

Determining eligibility for cases that do not complete the recertification process is challenging, even with third-party administrative wage data. One notable limitation is that our data excludes non-wage income, such as Social Security or self-employment income. ${ }^{11}$ However, our estimates of eligibility are consistent with others found in the literature: for example, Gray (2019) estimates that roughly half of SNAP cases that exit the program for

\footnotetext{
${ }^{11}$ Note that even if a case had a substantial amount of unearned income, it would require a change in that unearned income since the last certification to disqualify a case, which may be unlikely for the case of Social Security. We do not have data on self-employment income for our sample, however, San Francisco estimates that only 3 percent of SNAP recipients report self-employment income. Additionally, calculations from the California Department of Social Services (CDSS) show that only 2 percent of cases that exit SNAP in San Francisco in a recertification month appear on SNAP in a different county the following month, suggesting that inter-county moves are unlikely to be a large contributor to our estimates.
} 
over a month are still eligible for the program.

\section{Effects of Interview Assignment}

The descriptive statistics in the prior section suggest that at least a portion of cases that fail recertification may have maintained eligibility for the program. One possible explanation is that eligible participants fail recertification because elements of the administrative process may be difficult to complete. This section looks at the effect of one of the components of the recertification process - the timing of the initially assigned interview date - to determine its effect on recertification and subsequent program participation.

Figure 4 plots the relationship between the recertification rate and the initial interview day assignment adjusting for assignment group. Cases assigned to an initial interview at the start of the month have a recertification rate of 52 percent, while cases assigned to the latest interview dates have only a 44 percent recertification rate. The figure suggests that this gap in recertification success is not solely driven by cases assigned to interviews at the very end of the month, but rather shows an approximately linear downward trend in the probability of recertifying.

We use the following econometric model to estimate the impact of initial interview day assignment on recertification and post-recertification outcomes:

$$
Y_{i t}=\alpha+\gamma \text { InterviewDay } y_{i t}+\beta \text { AssignmentGroup } i t+\eta x_{i t}+\varepsilon_{i t}
$$

where $Y_{i t}$ is an indicator for whether case $i$ successfully recertified in month $t$, InterviewDay $y_{i t}$ is the calendar day of the assigned interview, AssignmentGroup $i$ is a vector of case characteristics used in the interview assignment process (recertification month by case language by interview type), and $x_{i t}$ is a set of demographic characteristics. ${ }^{12}$

\footnotetext{
${ }^{12}$ Demographic controls include case-level characteristics (household size and the presence of children), as well as head-of-household characteristics including sex, age, race, and citizenship.
} 


\section{A. Recertification}

Panel A of Table 4 estimates the effect of interview assignment on recertification success. Column 1 presents the simplest specification, controlling only for the interview assignment group. This model estimates that a one-day delay in the initially assigned interview reduces the likelihood of recertifying by 0.37 percentage points (95\% CI: $-0.44,-0.31$ ). Column 2, our preferred specification, includes the additional case demographic controls described above and yields a very similar estimate of 0.38 percentage points (95\% CI: $-0.45,-0.32$ ). This implies that a case assigned to the last interview assignment of the month is 11 percentage points less likely to recertify than a case assigned an interview on the first of the month - a 22 percent decline in recertification success off the mean.

We perform several robustness checks.. First, the characterization of the interview assignment process as as-good-as-random relies on the sorting process described in Section II. Alternative sorting processes or implementation errors may have resulted in a correlation between Case ID and the assigned interview date. While we do not have access to Case ID, we do have data on the year in which a case joined the program - the only economically meaningful information contained in the Case ID itself. To ensure that accidental deviations from the sort process we describe are not driving our results, column 3 includes fixed effects for the initial application year. We find that these controls do not impact our estimate of the effect of interview day assignment on recertification.

As mentioned in Section II, we observe a correlation between interview assignment and the recertification packet sent date: on average, cases with assigned interviews in the first half of the recertification month receive their recertification packets between two and three days earlier than those with interview dates assigned in the second half of the month. Column 4 controls for the day on which the recertification packet was sent to the case and shows only a small decrease in the effect of interview assignment relative to our preferred specification. ${ }^{13}$

\footnotetext{
${ }^{13}$ Sent date is not separately randomly assigned from the interview date; therefore, to the extent that receiving a recertification packet earlier increases recertification, our estimates should be interpreted as the effect of receiving an earlier interview date combined with receiving a recertification packet a few days earlier
} 
Lastly, to account for potential non-linearities in the effect of interview day on recertification success, column 5 replaces the linear term for interview day with interview week dummies. The results confirm that the likelihood of recertifying monotonically decreases with interview date assignment. Cases with initial interviews in the second, third, and fourth weeks of the month are 1.6, 4.6, and 7.6 percentage points less likely to recertify relative to cases with initial interviews in the first week of the month. These estimates are not only statistically significantly different from the recertification rate of those with initial interviews in the first week, but they are also significantly different from each other at the 1 percent level. ${ }^{14}$

\section{B. Program Participation}

The costs of recertification failure induced by interview date assignment depend on if and when the cases that failed recertification rejoin the program. This section uses data on reapplications to SNAP in the year following recertification to determine the effect of interview date assignment on post-recertification program participation.

Panel B of Table 4 repeats the analyses in Panel A, but considers the effect of interview date assignment on the likelihood of ever being on SNAP in the year following recertification. Specifically, the outcome variable is an indicator that equals one if the case either recertified or if the case failed recertification, but successfully reapplied for the program at any point in the following year. If all cases that fail recertification and remain off the program long term are ineligible, we would not expect interview date assignment to have an impact on this outcome. However, if eligible cases that fail recertification due to later interview assignments do not subsequently reapply for the program, for example, due to costs associated with the reapplication process or confusion about their continued eligibility, we may observe an effect on average.

${ }^{14}$ Additionally, specifications that add a linear term for interview day to this model no longer yield statistically significant estimates on any week dummy. As a result, we are unable to reject a linear model for the relationship between interview assignment date and recertification success. 
of interview assignment on longer-term participation as well. ${ }^{15}$

We find evidence that the administrative burden associated with the recertification process not only decreases recertification success, but longer-term program participation as well. Our preferred specification, column 2, shows that a one-day delay in the assigned interview date leads to a 0.09 percentage point decrease $(95 \% \mathrm{CI}:-0.15,-0.04)$ in the likelihood of receiving SNAP at any point in the year following recertification. This estimate implies that a case assigned an initial interview date on the first of the month versus the end of the month is 3 percentage points less likely to remain off the program for at least a year postrecertification off a base of 22 percent. Our robustness checks in the subsequent columns yield consistent, yet somewhat smaller estimates.

Table 5 presents an alternative specification in which we estimate the effect of recertification failure on SNAP receipt in the post-recertification year using the assigned interview date as an instrument for recertification failure. If the exclusion restriction holds, in that interview date assignment only affects SNAP participation through its effect on recertification success, this analysis can be interpreted as the effect of exogenously decertifying a case on future benefit receipt.

In column 1, our outcome of interest is the same as in Panel B of Table 4: an indicator for ever having participated in SNAP in the year following recertification. If all cases that fail recertification due to later interview assignment churn back onto the program within the following year, we should observe a coefficient of zero; alternatively, if these cases do not reenter the program after failing recertification, we should observe a coefficient of 100 percentage points. We find that the marginal case that fails recertification solely due to receiving a later interview assignment is 25 percentage points less likely to participate in SNAP at any point during the year post-recertification than a case that did not fail

\footnotetext{
${ }^{15}$ For example, Gray (2019) finds that the introduction of an online SNAP case management system, which provided a consolidated location for participants to access materials related to recertification and tools to assess their eligibility, led to a significant decrease in long-term exits following recertification. Similarly, Ganong and Liebman (2018) find that states that allow for recertification interviews to be held over the phone (reducing application costs relative to the traditional face-to-face interviews) have higher SNAP enrollments.
} 
recertification. In other words, one quarter of these marginal cases remain off SNAP long term, while the remaining three quarters re-enter the program at some point during the post-recertification year.

To investigate the time it takes for these marginal cases to re-enter the program, Figure 5 repeats the analysis in column 2 of Table 4 separately for each week in the year following recertification. Specifically, each point in the figure represents the coefficient on InterviewDay in equation (1) in which the outcome of interest is an indicator for participating in SNAP in the given post-recertification week. ${ }^{16}$ We find a large effect of interview date assignment on participation in the first week post-recertification. This estimate shrinks to roughly one third of the size in the following weeks, leveling off at around one quarter of the initial size for most of the rest of the year. This suggests that the marginal cases that churn back onto the program do so very shortly after failing recertification. ${ }^{17}$

\section{Welfare Implications}

Recertification failure induced by later interview assignment is associated with several costs including lost benefits to participants, additional workload for program administrators, and the fiscal externalities associated with labor supply responses. This section estimates several of these costs to assess the welfare consequences of the timing of interview assignments.

\section{A. Participants}

To measure the cost of lost benefits to cases that failed recertification, column 2 of Table 5 uses our instrumental variables approach to estimate the effect of recertification failure on benefit receipt in dollars in the post-recertification year. We estimate significant losses

\footnotetext{
${ }^{16}$ Our data include information on all reapplications to the program, but does not include information on subsequent decertifications that occur at times other than the annual recertification. As a result, a case that recertified or successfully reapplied post-failure but was discontinued mid-year would be classified as participating for the full year. However, since interview date assignment should not impact future decertifications, this data limitation should not bias our estimates.

${ }^{17}$ Appendix Figure 3 plots the raw post-recertification weekly participation rate by early versus late interview date assignment.
} 
in benefit dollars: recertification failure induced by later interview assignment leads to an average loss in annual benefits of $\$ 579$ (95\% CI: $97,1,061)$.

However, the costs of recertification failure for individual cases differ substantially depending on the post-recertification outcome. Specifically, the prior section found that 25 percent of cases that fail recertification due to later interview dates remain off SNAP for at least a full year while the remaining 75 percent churn back onto the program, often within the first weeks. While this latter group eventually re-enters the program, enrollment is not retroactive. This means that cases that are discontinued from the program because they miss the recertification deadline receive prorated benefits even when they successfully reapply shortly after.

Figure 6 repeats the analysis in Table 5, column 2 separately for each week in the postrecertification year. ${ }^{18}$ We find that the effect of recertification failure on benefit receipt in the first week post-recertification is $\$ 35 .{ }^{19}$ This suggests that the effects of recertification failure are highly skewed: cases that churn back on the program may lose as little as $\$ 35$, while cases that remain off the program for a full year could lose up to $\$ 2,300$ for a single-person household or $\$ 7,700$ for a family of four.

It is important to note that while the losses to cases that churn may be small in financial terms, they are not without costs to the individual. Qualitative interviews with SNAP recipients demonstrate that benefit loss associated with recertification failure creates considerable stress regardless of subsequent reapplication success (Edin et al., 2013). Additionally, research on the intramonth SNAP benefit cycle suggests that recipients experience nutrition-related health shocks and decreases in caloric intake at the end of the monthly benefit cycle when when many households have exhausted their monthly benefits (Shapiro,

\footnotetext{
${ }^{18}$ Appendix Figure 4 plots the raw means for the outcomes in this Figure 6, weekly benefit receipt, as a difference between the post-recertification week and the week prior to recertification by early versus late interview date assignment.

${ }^{19}$ This amount is roughly equivalent to half of the average weekly benefit in our sample. This suggests that a subset of cases re-entered the program in less than one week or, alternatively, that the marginal case that fails recertification due to interview assignment receives a lower-than-average monthly benefit (an issue that we explore in Section VIII).
} 
2005; Seligman et al., 2014). This suggests that even short-term benefit gaps may generate substantial externalities for SNAP recipients and their communities. ${ }^{20}$

\section{B. Program Administrators}

Program administrators face costs associated with processing applications, largely in the form of additional caseworker hours. In the case of recertification, these costs are incurred regardless of whether the case recertifies since caseworkers must attempt to contact all recertification cases. Cases that fail recertification, but reapply shortly after, create additional administrative costs associated with processing new applications that are more in-depth than those in the recertification process. Mills et al. (2014) estimates that the administrative costs associated with cases that churn are twice as large as that for cases that successfully recertify. Using data from six states, they estimate that each case that churns costs program administrators an additional $\$ 80$; however, the average certification-related costs in California are over $\$ 600$ per year, roughly three times as high as those in the states studied in Mills et al. (2014), suggesting that the costs associated with churn are likely even higher in our context. $^{21}$

This highlights an interesting difference in the distribution of costs for the two groups of cases that fail recertification - cases that remain off SNAP long term and cases that churn. Eligible cases that fail recertification and remain off the program incur substantial private costs in the form of missed benefits, however, they do not generate any additional processing costs for program administrators. In contrast, cases that churn suffer smaller losses in benefit receipt, but generate larger costs to program administrators.

\footnotetext{
${ }^{20}$ For example, this intramonth cyclicality in benefit receipt is also associated with increases in crime and disciplinary infractions (Carr and Packham, 2019; Gennetian et al., 2016).

${ }^{21}$ California has the highest certification-related state administrative expenses in the country, while the states considered in Mills et al. (2014) (Florida, Idaho, Illinois, Maryland, Texas, and Virginia) include several of the lowest.
} 


\section{Other Fiscal Externalities}

Prior literature highlights fiscal externalities generated by labor supply responses to the program. For example, Hoynes and Schanzenbach (2012) find that the initial roll-out of SNAP led to decreases in employment and number of hours worked. Using our administrative wage data, we estimate the effect of recertification failure on wage earnings in the year following recertification, instrumenting for failure with interview date assignment. Table 6 suggests that failing recertification due to later interview assignments does not translate to significant changes in wage earnings in the year post recertification (column 1) nor the likelihood of receiving any wage earnings in the post-recertification year (column 2), though the estimates are imprecise.

\section{Mechanisms}

This section investigates possible mechanisms by which interview assignment impacts recertification. One potential pathway is through interview completion - a necessary step in the recertification process. Table 2 shows that 11 percent of cases that completed an interview had missed their first attempted interview, but successfully rescheduled and completed a later interview. This suggests that the ability to reschedule missed interviews may be particularly important in determining recertification success. Cases with earlier interview assignments that miss their initial interview appointment have more time to reschedule before the end of the certification period, while cases with later assignments may be unable to find an alternative interview date before the recertification deadline. The implications of this relationship for recertification success depend on the forward-looking nature of the recipient: if recipients anticipate the difficulty of rescheduling an interview later in the month, we would expect that the likelihood of completing the first interview attempt will increase if the date is closer to the end of the month, potentially mitigating the effect of later assignments on interview completion and, in turn, recertification. ${ }^{22}$

\footnotetext{
${ }^{22}$ For example, a case with an unanticipated conflict on the day of the assigned interview may strategically choose to miss the interview and reschedule later in the month if the assigned date is at the beginning of the
} 
Table 7 estimates the effect of initial interview assignment on the likelihood of completing the first attempted interview and any interview (assigned or rescheduled), respectively. Column 1 shows that the effect of interview assignment on completion of the first interview attempt is near-zero and not statistically significant using a linear specification (95\% CI: $0.05,0.06)$. Column 2 repeats this analysis using interview week dummies and demonstrates that the linear specification is not masking a spike in completion among cases with very late assignments. Column 3 shows that cases assigned to interviews at the beginning of the month are 7 percentage points more likely to complete interview by the recertification deadline than cases assigned to the last interview date (a 0.24 percentage point decrease per day; $95 \%$ CI: $-0.28,-0.19)$; column 4 confirms that the relationship between interview assignment and completion increases monotonically by week.

These results suggest that time to reschedule a missed appointment may play a significant role in recertification success: cases assigned to later interviews are less likely to complete an interview by the recertification deadline. However, cases do not appear to anticipate the relationship between assigned interview date and interview completion, possibly due to overconfidence in the ease of rescheduling (Camerer and Lovallo, 1999; Moore and Healy, 2008) or to under-awareness of or inattention to the assigned interview date (Karlan et al., 2016).

We find further evidence that inattention to the recertification process may be driving our results; specifically, we find evidence that additional early alerts increase recertification success. First, while all cases that miss an interview receive a notice in the mail, cases that are assigned to a phone interview (81 percent of cases) also receive a voicemail asking the individual to call and reschedule the appointment. These voicemails may be a key alternative communication tool to inform cases that the recertification process has begun. ${ }^{23}$ If so, earlier appointments, which allow for more time to complete the recertification steps month; however, if the interview is at the end of the month, the case may prioritize completing the scheduled interview in spite of the conflict.

${ }^{23}$ For example, this may be particularly important for cases that have moved or cases that use a P.O. Box as their primary address as they may be less likely to have received the mailed communications. 
after the alert, would be particularly helpful for phone interviews. By the same logic, cases that receive additional early communications about the recertification process may be less affected by initial interview timing. In our sample, just under one quarter of cases signed up to receive optional text communications from the program office about their case status. These communications included a reminder about the recertification process that notifies cases when the recertification packet has been sent to the case's address. If cases with early interview dates are more likely to recertify because they are reminded about the process earlier, then text reminders should moderate the influence of interview day assignment on recertification success by providing the same information through an alternative channel.

Table 8 estimates the effect of interview assignment on recertification success for phone versus in-person interviews (column 1) and for cases that enrolled in the text messaging program versus those that did not (column 2). Column 1 shows that while earlier interview assignments lead to higher rates of recertification success for in-person interviews, the effects are more than twice as large for phone interviews. Column 2 shows that interview date assignment has a smaller impact on cases that receive text messages, though this difference is not statistically significant. It is important to note that assignment to a phone interview is not random and participation in the text program is voluntary with far from universal take-up, so these results should be viewed as merely suggestive.

Overall, our results imply that early interviews are particularly helpful for cases that miss their initial interview date. Moreover, receiving missed interview voicemails and text message alerts may partially mitigate the negative effects of late interviews. This highlights the potential importance of reminders during the recertification process, and points to inattention as a possible mechanism driving our results.

\section{Effect of Interview Assignment by Case Characteristics}

Our results thus far have estimated the effect of interview assignment on program participation for the universe of recertification cases. In this section, we estimate whether this 
specific form of administrative burden varies based on demographic characteristics associated with higher marginal utility from recertification. This allows us to assess whether later interview assignments improve or exacerbate targeting efficiency. Nichols and Zeckhauser (1982) develop a model in which hassles associated with program application (or in our case, recertification) can improve program targeting by screening out individuals with lower marginal utility from program benefits since these individuals have a higher opportunity cost of time. In contrast, Deshpande and Li (2019) present an alternative version of the model in Nichols and Zeckhauser (1982) showing that if application costs are related to cognitive costs, rather than time costs, then the results reverse and application costs can worsen targeting efficiency. ${ }^{24}$

The empirical literature on targeting efficiency relies largely on estimating the effect of a change in application costs on program participation by observable characteristics that are plausibly correlated with marginal utility from program benefits. For example, Finkelstein and Notowidigdo (2019) find that lowering SNAP application costs by providing information about application assistance increased take-up, but reduced targeting efficiency: marginal enrollees were more likely to receive lower monthly benefits and be in better health. In contrast, Currie and Grogger (2001) find that single-parent households are disproportionately affected by shorter SNAP recertification periods, Bhargava and Manoli (2015) show that simplifying EITC notices increase take-up among the very poor, and Deshpande and Li (2019) show that program office closures lead to disproportionately large decreases in applications for disability insurance from low-education applicants.

Table 9 follows this literature and estimates heterogeneity in the effect of interview date assignment on recertification success and subsequent program participation by interacting InterviewDay from equation (1) with case characteristics plausibly associated with marginal utility from program participation. Specifically, we focus on heterogeneity by the case's prior

\footnotetext{
${ }^{24}$ They highlight that this model is consistent with findings from Bertrand, Mullainathan and Shafir (2004) which suggests that administrative hassles worsen targeting efficiency since poverty may exacerbate various behavioral biases, such as present bias or attention.
} 
year SNAP benefit level. We consider two measures of benefit receipt: the benefit amount itself (which is a function of household size and income) and, separately, an indicator for receiving the maximum benefit amount. We estimate heterogeneity in the effect of interview assignment on an indicator for recertification success and an indicator for ever participating in the program during the post-recertification year.

Columns 1 and 2 present the results by benefit level for recertification success and program participation in the post-recertification year, respectively. We find that the effects of interview date assignment on recertification success are significantly larger for cases receiving higher benefit amounts. However, we find no difference in the effect of interview assignment on the likelihood of ever participating in SNAP in the subsequent year, suggesting that these additional recertification failures result in churn. Columns 3 and 4 repeat these analyses using an indicator for whether a case received the maximum benefit amount (roughly two-thirds of our sample). Here we find no evidence of heterogeneity in the effect of interview assignment on recertification success, but we do find that the effects on subsequent program participation are largely driven by cases receiving the maximum benefit amount, a difference that is significant at the 10 percent level. To the extent that higher benefit levels indicate higher marginal utility of participation, these results point to the conclusion that the hassle costs created by later interview dates worsen targeting efficiency.

\section{Conclusion}

We find evidence that administrative burden associated with the SNAP recertification process in the form of later interview assignments leads to decreases in recertification and program participation. Cases that are assigned to initial interview dates at the beginning of the recertification month are over 20 percent more likely to recertify than cases assigned to interviews at the end of the month. Cases that fail recertification due to later interview assignments lose an average of almost $\$ 600$ in benefits in the following year.

Our results suggest that cases are unaware of or inattentive to the timing of interviews - 
or potentially to the recertification process as a whole. This suggests that improving communication strategies that alert cases to key deadlines in the recertification process may significantly increase participation and reduce administrative costs associated with processing cases that churn. For example, Castleman and Page (2016) find that text communications significantly increase Free Application for Federal Student Aid (FAFSA) renewals. In a similar spirit, USDA-FNS, the agency that funds SNAP, recommends a strategy in which caseworkers "cold call" SNAP cases to improve interview completion rates FNS (2018).

These results also provide direct implications for the design of the SNAP interview assignment process. Current federal law requires that SNAP recipients must complete a caseworker interview to recertify, but the scheduling and timing of these interviews is not federally regulated, allowing considerable flexibility for SNAP administrators. One simple policy implication is to schedule caseworker interviews earlier in the recertification process; if our estimates hold out of sample to the month prior, this suggests that a one-week shift in the recertification process would lead to a 3 percentage point increase in recertification success. Alternatively, if staffing availability allowed, scheduling all initial interviews to be conducted on the first day of the recertification month would lead to a 5 percentage point increase in the recertification rate.

Lastly, we find that of the cases that fail recertification due to later interview assignment, one quarter remain off the program for at least a full year post-recertification while the rest reenter the program, many within the first weeks after failing recertification. This implies that the costs to participants of failing to recertify are highly skewed, with some cases losing only a week of benefits while others have benefit dollar losses in the thousands. Extrapolating the economic implications of our findings to different policy contexts yields more or less extreme consequences depending on the flexibility of the policy's reapplication process. For example, while SNAP recipients who fail recertification may reapply for the program at any time, students who miss the FAFSA renewal deadline are ineligible for financial aid until the following year. Recipients of Unemployment Insurance must file weekly claims 
to receive benefits following a strict timetable - late submissions result in the loss of that week's benefits, while repeated missed deadlines lead to case closure. In contrast, while Medicaid recipients must complete a periodic recertification process, the program provides retroactive enrollment allowing eligible individuals to re-enroll at the time they are receiving medical care (Pei, 2017). Our results suggest that incorporating flexibility or minimizing reapplication hurdles may decrease costs associated with program integrity policies for both participants and program administrators. 


\section{References}

Alatas, Vivi, Ririn Purnamasari, Matthew Wai-Poi, Abhijit Banerjee, Benjamin A Olken, and Rema Hanna. 2016. "Self-targeting: Evidence from a field experiment in Indonesia." Journal of Political Economy, 124(2): 371-427.

Armour, Philip. 2018. "The Role of Information in Disability Insurance Application: An Analysis of the Social Security Statement Phase-In." American Economic Journal: Economic Policy, 10(3): 1-41.

Barr, Andrew, and Sarah Turner. 2018. "A Letter and Encouragement: Does Information Increase Postsecondary Enrollment of UI Recipients?" American Economic Journal: Economic Policy, 10(3): 42-68.

Bertrand, Marianne, Sendhil Mullainathan, and Eldar Shafir. 2004. "A Behavioral Economics View of Poverty." American Economic Review, 94(2): 419-423.

Bettinger, Eric P, Bridget Terry Long, Philip Oreopoulos, and Lisa Sanbonmatsu. 2012. "The Role of Application Assistance and Information in College Decisions: Results from the H\&R Block FAFSA Experiment." The Quarterly Journal of Economics, 127(3): 1205-1242.

Bhargava, Saurabh, and Dayanand Manoli. 2015. "Psychological frictions and the incomplete take-up of social benefits: Evidence from an IRS field experiment." American Economic Review, 105(11): 3489-3529.

Camerer, Colin, and Dan Lovallo. 1999. "Overconfidence and excess entry: An experimental approach." The American Economic Review, 89(1): 306-318.

Carr, Jillian B, and Analisa Packham. 2019. "SNAP Benefits and Crime: Evidence from Changing Disbursement Schedules." Review of Economics and Statistics, 101(2). 
Castleman, Benjamin L, and Lindsay C Page. 2016. "Freshman year financial aid nudges: An experiment to increase FAFSA renewal and college persistence." Journal of Human Resources, 51(2): 389-415.

CBO. 2018. "Federal Mandatory Spending for Means-Tested Programs, 2008 to 2028." Congressional Budget Office.

Chetty, Raj, John N Friedman, and Emmanuel Saez. 2013. "Using Differences in Knowledge across Neighborhoods to Uncover the Impacts of the EITC on Earnings." American Economic Review, 103(7): 2683-2721.

Cunnyngham, Karen E. 2019. "Reaching Those in Need: Estimates of State Supplemental Nutrition Assistance Program Participation Rates in 2016." Mathematica Policy Research.

Currie, Janet, and Jeffrey Grogger. 2001. "Explaining recent declines in food stamp program participation." Brookings-Wharton papers on urban affairs, 203-244.

Deshpande, Manasi, and Yue Li. 2019. "Who is screened out? Application costs and the targeting of disability programs." American Economic Journal: Economic Policy, 11(4): 213-48.

Edin, Kathryn, Melody Boyd, James Mabli, Jim Ohls, Julie Worthington, Sara Greene, Nicholas Redel, and Swetha Sridharan. 2013. "SNAP Food Security InDepth Interview Study." Mathematica Policy Research.

Finkelstein, Amy, and Matthew J Notowidigdo. 2019. "Take-up and targeting: Experimental evidence from SNAP." The Quarterly Journal of Economics, 134(3): 1505-1556.

FNS. 2018. "SNAP Recertification Toolkit." USDA.

Ganong, Peter, and Jeffrey B. Liebman. 2018. "The Decline, Rebound, and Further Rise in SNAP Enrollment: Disentangling Business Cycle Fluctuations and Policy Changes." American Economic Journal: Economic Policy, 10(4): 153-76. 
Geller, Daniel, and Julia Isaacs. 2019. "Exploring the Causes of State Variation in SNAP Administrative Costs." USDA.

Gennetian, Lisa A, Roopa Seshadri, Nathan D Hess, Aaron N Winn, and Robert M Goerge. 2016. "Supplemental Nutrition Assistance Program (SNAP) benefit cycles and student disciplinary infractions." Social Service Review, 90(3): 403-433.

Gray, Colin. 2019. "Leaving benefits on the table: Evidence from SNAP." Journal of Public Economics, 179: 104054.

Hastings, Justine, and Jesse M Shapiro. 2018. "How are SNAP benefits spent? Evidence from a retail panel." American Economic Review, 108(12): 3493-3540.

Heinrich, Carolyn J. 2015. "The bite of administrative burden: A theoretical and empirical investigation." Journal of Public Administration Research and Theory, 26(3): 403-420.

Herd, Pamela, and Donald P Moynihan. 2019. Administrative burden: Policymaking by other means. Russell Sage Foundation.

Hoynes, Hilary Williamson, and Diane Whitmore Schanzenbach. 2012. "Work incentives and the food stamp program." Journal of Public Economics, 96(1-2): 151-162.

Kabbani, Nader S., and Parke E. Wilde. 2003. "Short Recertification Periods in the U.S. Food Stamp Program.” The Journal of Human Resources, 38: 1112-1138.

Karlan, Dean, Margaret McConnell, Sendhil Mullainathan, and Jonathan Zinman. 2016. "Getting to the top of mind: How reminders increase saving." Management Science, 62(12): 3393-3411.

Madrian, Brigitte C, and Dennis F Shea. 2001. "The Power of Suggestion: Inertia in 401(k) Participation and Savings Behavior." The Quarterly Journal of Economics, 116(4): 1149-1187. 
Mills, Gregory, Tracy Vericker, Heather Koball, Kye Lippold, Laura Wheaton, and Sam Elkin. 2014. Understanding the rates, causes, and costs of churning in the Supplemental Nutrition Assistance Program. United States Department of Agriculture, Food and Nutrition Service, Office of Policy Support.

Moffitt, Robert. 1983. "An economic model of welfare stigma." American Economic Review, 73(5): 1023-1035.

Moore, Don A, and Paul J Healy. 2008. "The trouble with overconfidence." Psychological Review, 115(2): 502 .

Nichols, Albert L, and Richard J Zeckhauser. 1982. "Targeting Transfers through Restrictions on Recipients." American Economic Review, 72(2): 372-377.

Pei, Zhuan. 2017. "Eligibility Recertification and Dynamic Opt-in Incentives in Incometested Social Programs: Evidence from Medicaid/CHIP." American Economic Journal: Economic Policy, 9(1): 241-76.

Ribar, David C, Marilyn Edelhoch, and Qiduan Liu. 2008. "Watching the Clocks: The Role of Food Stamp Recertification and TANF Time Limits in Caseload Dynamics." Journal of Human Resources, 43(1): 208-238.

Rossin-Slater, Maya. 2013. "WIC in Your Neighborhood: New Evidence on the Impacts of Geographic Access to Clinics." Journal of Public Economics, 102: 51-69.

Seligman, Hilary K, Ann F Bolger, David Guzman, Andrea López, and Kirsten Bibbins-Domingo. 2014. "Exhaustion of food budgets at months end and hospital admissions for hypoglycemia." Health affairs, 33(1): 116-123.

Shapiro, Jesse M. 2005. "Is There a Daily Discount Rate? Evidence from the Food Stamp Nutrition Cycle." Journal of Public Economics, 89(2): 303-325. 
Figure 1: Distribution of Initial Interview Assignments

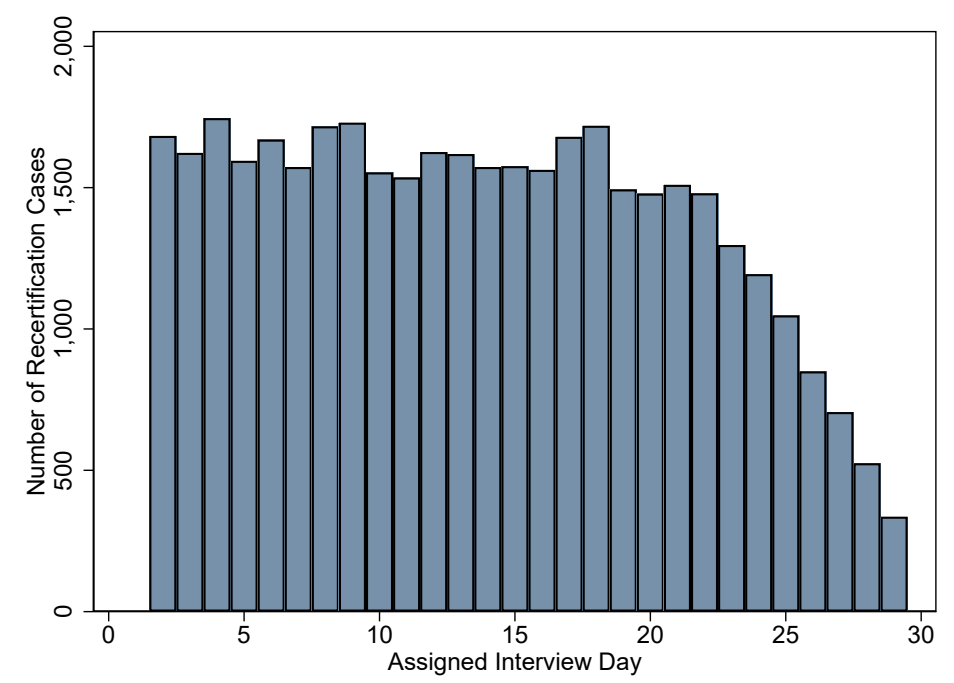

Source: SF-HSA. This figure plots the number of recertification cases assigned an initial interview on each calendar day of the recertification month.

Figure 2: Number of Prorated Benefit Days Among Churn Cases

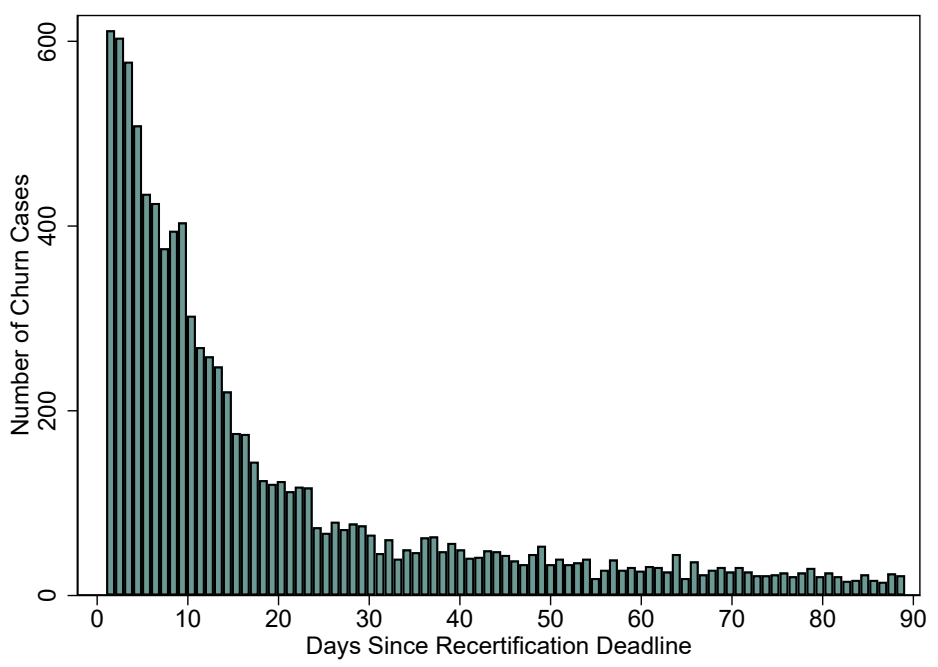

Source: SF-HSA. This figure plots the number of recertification cases that churn (i.e., fail recertification but subsequently re-enter the program) within 90 days by the number of days the case was off SNAP following recertification failure. 
Figure 3: Earnings by Recertification Outcome

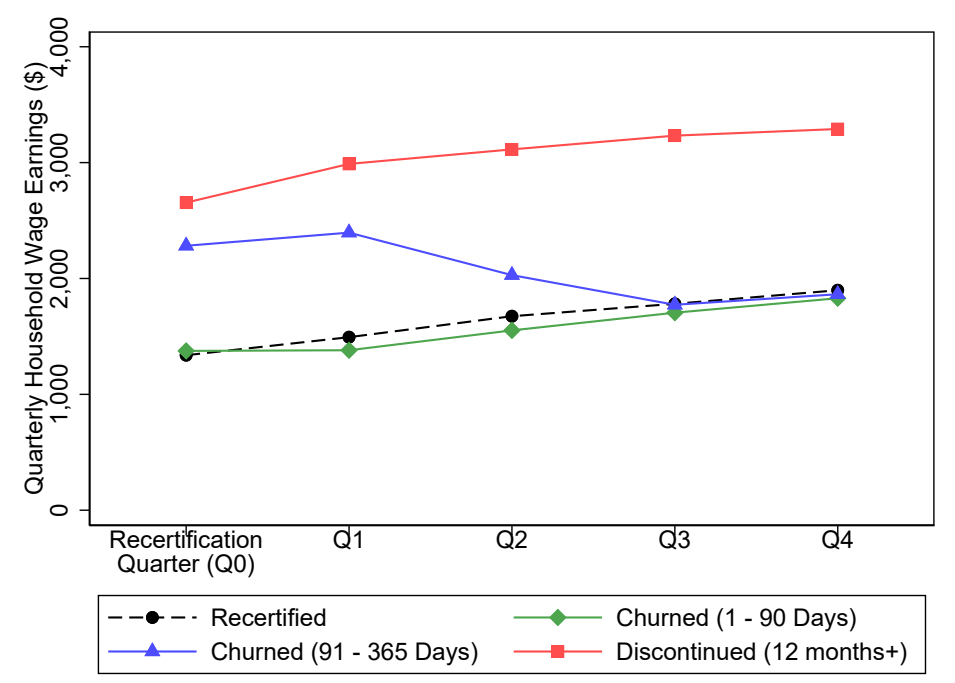

Source: EDD quarterly wage data. This figure plots quarterly average wage earnings for the recertification quarter and the subsequent four quarters for four groups: cases that successfully recertified, cases that failed recertification but re-enrolled in SNAP, i.e., churned, within 90 days, cases that failed recertification but re-enrolled in SNAP within 90 to 365 days post-recertification failure, and cases that failed recertification and remained off SNAP for at least one full year.

Figure 4: Recertification Rate by Interview Assignment

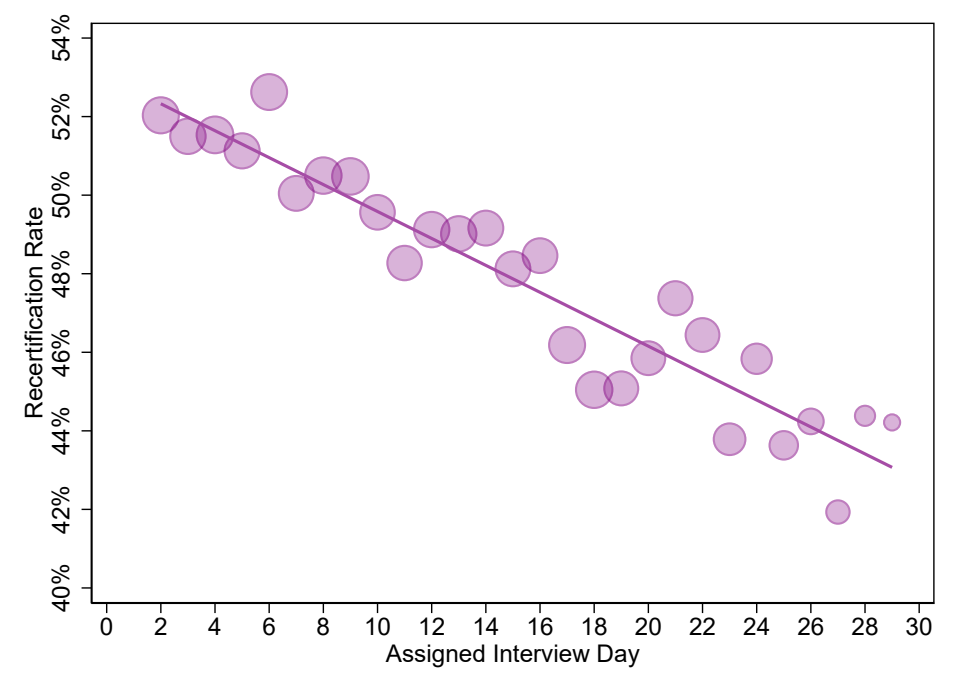

Source: SF-HSA. This figure presents the recertification rate by initial interview assignment day where the recertification rate is demeaned by interview assignment group (month by case language by interview type). The size of each circles indicates the relative number of observations per calendar day. The dashed line is a linear best fit from regressing an indicator for recertification success on the assigned interview day controlling for assignment group fixed effects. 
Figure 5: Effect of Interview Assignment on SNAP Participation by Week

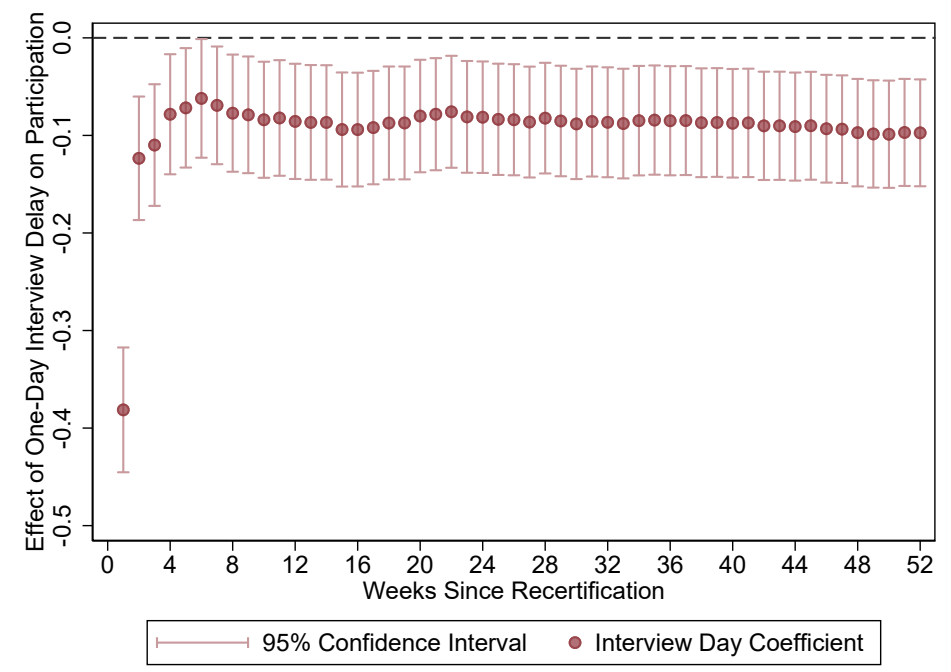

Source: SF-HSA. This figure presents regression estimates from a linear probability model that regresses initial caseworker interview assignment day on an indicator for participating in SNAP in a given week for each week in the post-recertification year. Cases are assumed to participate in each week following successful recertification or reapplication. All regressions include controls for interview assignment group (month by case language by interview type fixed effects) and demographic characteristics (household size, presence of children, and sex, age, race, and citizenship of the head of household). Units are in percentage points (0-100). Bars represent the $95 \%$ confidence interval.

\section{Figure 6: Effect of Recertification Failure on SNAP Benefit Receipt}

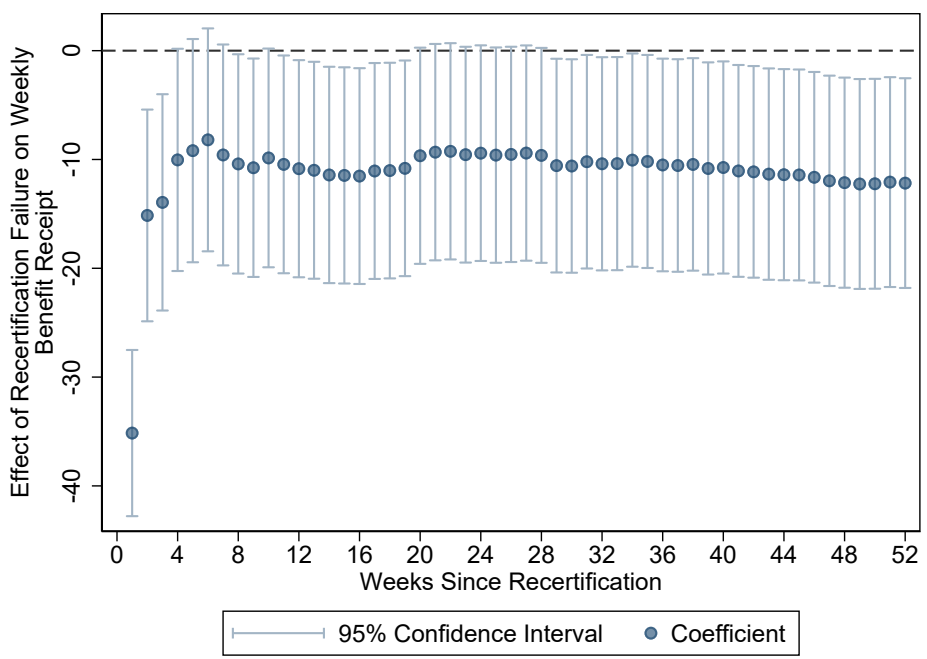

Source: SF-HSA. This figure presents regression estimates from an instrumental variables regression that estimates the effect of recertification failure, using interview assignment calendar day as an instrument, on SNAP benefit dollars received in each week of the post-recertification year. Cases are assumed to participate in each week following successful recertification or reapplication. Estimates of monthly benefit receipt are based on the benefit level in the recertification quarter. All regressions include controls for interview assignment group (month by case language by interview type fixed effects) and demographic characteristics (household size, presence of children, and sex, age, race, and citizenship of the head of household). Bars represent the $95 \%$ confidence interval. 
Table 1: Recertification Case Characteristics

\begin{tabular}{lccccc}
\hline & $\begin{array}{c}\text { QC Data } \\
\text { Nationwide } \\
(1)\end{array}$ & $\begin{array}{c}\text { Full } \\
\text { Sample } \\
(2)\end{array}$ & $\begin{array}{c}\text { Early } \\
\text { Interview } \\
(3)\end{array}$ & $\begin{array}{c}\text { Late } \\
\text { Interview } \\
(4)\end{array}$ & $\begin{array}{c}\text { prob }>\text { F } \\
(5)\end{array}$ \\
\hline Case Characteristics & & & & & \\
Household Size & 1.97 & 1.55 & 1.55 & 1.55 & 0.99 \\
Any Children (\%) & 40.0 & 32.1 & 32.4 & 31.9 & 0.27 \\
Years Since First on SNAP & - & 4.82 & 4.79 & 4.85 & 0.12 \\
Monthly Benefits & $\$ 241$ & $\$ 229$ & $\$ 230$ & $\$ 229$ & 0.28 \\
Max SNAP Benefits (\%) & 38.8 & 63.3 & 63.4 & 63.2 & 0.75 \\
Quarterly Wage Income & $\$ 1,049$ & $\$ 1,695$ & $\$ 1,689$ & $\$ 1,701$ & 0.72 \\
No Wage Income (\%) & 71.7 & 65.6 & 65.8 & 65.3 & 0.27 \\
Non-English Speaking (\%) & - & 30.7 & 31.0 & 30.4 & 0.22 \\
& & & & & \\
Household Head Demographics & & & & & \\
Female (\%) & 68.3 & 46.3 & 46.1 & 46.5 & 0.35 \\
Age & 45.6 & 42.6 & 42.5 & 42.6 & 0.50 \\
US Citizen (\%) & 84.6 & 77.0 & 76.6 & 77.5 & 0.03 \\
Non-White (\%) & 53.6 & 78.9 & 78.8 & 78.9 & 0.68 \\
\hline Total Cases & 44,494 & 39,702 & 19,672 & 20,030 & \\
\hline
\end{tabular}

Source: USDA's 2016 SNAP Quality Control System and SF-HSA. Table reports means of SNAP case demographic characteristics for a nationally-representative sample of SNAP cases (column 1) and for our sample of recertification cases (column 2). Nationwide estimates exclude households participating in TANF for comparability to our sample. Columns 3 and 4 reports means for our population separately for cases assigned to interviews in the first half of the month (before the 14th) and in the second half of the month. Column 5 presents the p-value associated with a test for equality of means from columns 3 and 4 . Recertification cases characteristics include case-level characteristics (household size, presence of children, years since first SNAP application, prior year monthly SNAP benefit and an indicator for receiving the maximum SNAP benefit, quarterly wage earningsin the recertification quarter and an indicator for receiving any wages, and non-English case language), as well as head-of-household characteristics (sex, age, citizenship, and race). Statistics on race exclude the 5,880 cases in the nationwide data and 3,125 cases in our sample for which ethnicity is unknown. 
Table 2: Summary Statistics of Recertification Outcomes

\begin{tabular}{lc}
\hline & Full Sample \\
\hline Recertification Process Outcomes & \\
Completed First Attempted Interview & 67.8 \\
Completed Any Interview & 76.3 \\
Recertified & 48.3 \\
& \\
Post-Recertification Outcomes & \\
Churned (1 - 90 days) & 23.7 \\
Churned (91 - 365 Days) & 5.7 \\
Discontinued (12 months+) & 22.4 \\
\hline Total Cases & 39,702 \\
\hline
\end{tabular}

Source: SF-HSA. This table reports sample means for each outcome as a percent of the full recertification case sample. The table includes completion of recertification process steps as well as post-recertification outcomes for cases that failed including whether a case churned (i.e., failed recertification, but successfully re-enrolled in SNAP within the following 1-90 or 91-365 days post-recertification, respectively) or whether the case failed recertification and remained off the program for at least one full year.

Table 3: Earnings by Recertification Outcome

\begin{tabular}{lccccc}
\hline & $\begin{array}{c}(1) \\
\text { Full Sample }\end{array}$ & $\begin{array}{c}(2) \\
\text { Recertified }\end{array}$ & $\begin{array}{c}(3) \\
\text { Churned } \\
(1-90 \text { days })\end{array}$ & $\begin{array}{c}(4) \\
\text { Churned } \\
(91-365 \text { days })\end{array}$ & $\begin{array}{c}(5) \\
\text { Discontinued } \\
(12 \text { months }+)\end{array}$ \\
\hline Earnings < 200\% FPL & 94.0 & 97.5 & 96.3 & 88.9 & 85.3 \\
No Wage Earnings & 65.6 & 68.6 & 68.1 & 58.9 & 57.9 \\
\hline Total Cases & 39,702 & 19,157 & 9,414 & 2,252 & 8,879 \\
\hline
\end{tabular}

Source: EDD quarterly wage earnings data. This table reports the fraction of cases that had wage earnings below 200 percent FPL (the California gross income limit for SNAP eligibility) or no wage earnings at all, respectively, in the quarter of recertification for the following samples: all recertification cases (column 1), cases that successfully recertified (column 2), cases that failed recertification but re-enrolled in SNAP within 90 days (column 3), cases that failed recertification but re-enrolled in SNAP within 91 to 365 days postrecertification failure (column 4), and cases that failed recertification and remained off SNAP for at least one full year (column 5). 
Table 4: Effect of Interview Assignment on Recertification and SNAP Participation

$\begin{array}{lllll}(1) & (2) & (3) & (4)\end{array}$

\section{Panel A: Recertified}

Interview Day

Interview Week 2

Interview Week 3

Interview Week 4

$$
-0.37^{* * *} \quad-0.38^{* * *} \quad-0.37^{* * *} \quad-0.33^{* * *}
$$

\section{Panel B: Ever on SNAP in Year Post-Recertification}

Interview Day

Interview Week 2

Interview Week 3

Interview Week 4

$$
\begin{array}{cccc}
-0.08^{* * *} & -0.09^{* * *} & -0.07 * * * & -0.07^{* *} \\
(0.03) & (0.03) & (0.03) & (0.03)
\end{array}
$$

\begin{tabular}{lccccc}
\hline Case Randomization Controls & $\mathrm{X}$ & $\mathrm{X}$ & $\mathrm{X}$ & $\mathrm{X}$ & $\mathrm{X}$ \\
Demographics & & $\mathrm{X}$ & $\mathrm{X}$ & $\mathrm{X}$ & $\mathrm{X}$ \\
Initial Year & & & $\mathrm{X}$ & & \\
Sent Day & & & & $\mathrm{X}$ & \\
Total Cases & 39,702 & 39,702 & 39,702 & 39,702 & 39,702 \\
\hline
\end{tabular}

Source: SF-HSA. ${ }^{* * *} \mathrm{p}<0.01,{ }^{* *} \mathrm{p}<0.05,{ }^{*} \mathrm{p}<0.1$. Standard errors clustered at the case level in parentheses. All regressions are linear probability models that regress initial caseworker interview assignment, either a linear term for calendar day or interview week dummies, on an indicator for successful recertification (Panel A) or an indicator for whether the case ever participated in SNAP in the post-recertification year (Panel B). Units are in percentage points (0-100). Interview assignment group controls include recertification month by case language by interview type (phone versus in-person) fixed effects. Demographic controls include household size fixed effects, an indicator for any children, as well as controls for the sex, age, race, and citizenship of the head of household. Initial year controls are fixed effects for the year in which the case first enrolled in the program. Sent day is a linear control for the date the caseworker sent a case's recertification packet. 
Table 5: Effect of Recertification Failure on Post-Recertification SNAP Participation

\begin{tabular}{lcc}
\hline Outcome: & $(1)$ & $(2)$ \\
& Post-Recert & SNAP \\
& Participation & Benefits $(\$)$ \\
\hline Failed Recertification & $-24.8^{* * *}$ & $-579^{* *}$ \\
& $(6.6)$ & $(246)$ \\
Outcome Mean & 77.6 & 2,105 \\
Total Cases & 39,702 & 39,699 \\
\hline
\end{tabular}

Source: SF-HSA. ${ }^{* * *} \mathrm{p}<0.01,{ }^{* *} \mathrm{p}<0.05,{ }^{*} \mathrm{p}<0.1$. Standard errors clustered at the case level in parentheses. Analyses use an instrumental variables regression to estimate the effect of recertification failure on post-recertification SNAP receipt using interview assignment calendar day as an instrument for recertification failure. Outcomes are an indicator for ever participating in SNAP in the post-recertification year (column 1) and the SNAP benefits dollars received in the post-recertification year (column 2). Estimates of monthly benefit receipt are based on the benefit level in the recertification quarter; column 2 excludes the three cases that are missing this information. Units in column 1 are in percentage points (0-100). All regressions include controls for interview assignment group (month by case language by interview type fixed effects) and demographic characteristics (household size, presence of children, and sex, age, race, and citizenship of the head of household).

Table 6: Effect of Recertification Failure on Post-Recertification Earnings

\begin{tabular}{lcc}
\hline & $(1)$ & $(2)$ \\
Outcome: & Annual Earnings & Any Earnings \\
\hline
\end{tabular}

Failed Recertification

47

$(2,259)$

\begin{abstract}
\begin{tabular}{lcc} 
Outcome Mean & 7,622 & 44.2 \\
Total Cases & 39,702 & 39,702 \\
\hline
\end{tabular}
Source: SF-HSA and EDD quarterly wage earnings data. ${ }^{* * *} \mathrm{p}<0.01,{ }^{* *} \mathrm{p}<0.05,{ }^{*} \mathrm{p}<0.1$. Standard errors clustered at the case level in parentheses. Analyses use an instrumental variables regression to estimate the effect of recertification failure on post-recertification wage earnings using interview assignment calendar day as an instrument for recertification failure. Outcomes are annual wage earnings in the post-recertification year (column 1) and an indicator for receiving any wage earnings in the post-recertification year (column 2). Units in column 2 are in percentage points (0-100). All regressions include controls for interview assignment group (month by case language by interview type fixed effects) and demographic characteristics (household size, presence of children, and sex, age, race, and citizenship of the head of household).
\end{abstract}


Table 7: Effect of Interview Assignment on Interview Completion

\begin{tabular}{lcccc}
\hline & $(1)$ & $(2)$ & $(3)$ & $(4)$ \\
Outcome: & Complete First & Complete First & Complete Any & Complete Any \\
\hline Interview Day & 0.01 & & $-0.24^{* * *}$ & \\
Interview Week 2 & $(0.03)$ & -0.65 & $(0.02)$ & $-1.23^{* * *}$ \\
& & $(0.51)$ & & $(0.43)$ \\
Interview Week 3 & & -0.08 & $-2.92^{* * *}$ \\
& & $(0.52)$ & & $(0.44)$ \\
Interview Week 4 & & $(0.44$ & & $-4.42^{* * *}$ \\
& & & & \\
& & $67.51)$ & 76.3 \\
Outcome Mean & 67.9 & 39,702 & 39.702 & 39,702 \\
Total Cases & 39,702 & & & \\
\hline
\end{tabular}

Source: SF-HSA. ${ }^{* * *} \mathrm{p}<0.01,{ }^{* *} \mathrm{p}<0.05,{ }^{*} \mathrm{p}<0.1$. Standard errors clustered at the case level in parentheses. All regressions are linear probability models that regress initial caseworker interview assignment, either a linear term for calendar day or interview week dummies, on an indicator for completion of the first attempted caseworker interview (columns 1 and 2) or any caseworker interview (columns 3 and 4). Units are in percentage points (0-100). All regressions include controls for interview assignment group (month by case language by interview type fixed effects) and demographic characteristics (household size, presence of children, and sex, age, race, and citizenship of the head of household).

Table 8: Effect of Interview Assignment by Communication Alert

\begin{tabular}{lcc}
\hline & $(1)$ & $(2)$ \\
& Phone & Text \\
\hline Interview Day & $\begin{array}{c}-0.17^{* *} \\
(0.07)\end{array}$ & $-0.43^{* * *}$ \\
& $(0.05)$ \\
Interview Day X Phone & $-0.26^{* * *}$ & \\
& $(0.08)$ & \\
Interview Day X Text & & 0.15 \\
& & $(0.10)$ \\
Outcome Mean & 48.3 & 49.0 \\
Total Cases & 39,702 & 22,657 \\
\hline
\end{tabular}

Source: SF-HSA. ${ }^{* * *} \mathrm{p}<0.01,{ }^{* *} \mathrm{p}<0.05,{ }^{*} \mathrm{p}<0.1$. Standard errors clustered at the case level in parentheses. All regressions are linear probability models that regress initial caseworker interview assignment day, an indicator for receiving a phone interview (column 1) or an indicator for enrolling to receive case status text communications (column 2), and their interaction on an indicator for recertification success. Units are in percentage points (0-100). All regressions include controls for interview assignment group (month by case language by interview type fixed effects) and demographic characteristics (household size, presence of children, and sex, age, race, and citizenship of the head of household). Data on whether a case was enrolled in the text messaging program was available for cases with a certification period ending in October 2015 or after. 
Table 9: Effect of Interview Assignment by SNAP Benefit

\begin{tabular}{|c|c|c|c|c|}
\hline Outcome: & $\begin{array}{c}(1) \\
\text { Recertified }\end{array}$ & $\begin{array}{c}(2) \\
\text { Post-Recert } \\
\text { Participation }\end{array}$ & $\begin{array}{c}(3) \\
\text { Recertified }\end{array}$ & $\begin{array}{c}(4) \\
\text { Post-Recert } \\
\text { Participation }\end{array}$ \\
\hline Interview Day & $\begin{array}{c}-0.26^{* * *} \\
(0.07)\end{array}$ & $\begin{array}{c}-0.10^{*} \\
(0.06)\end{array}$ & $\begin{array}{c}-0.42^{* * *} \\
(0.05)\end{array}$ & $\begin{array}{l}-0.03 \\
(0.04)\end{array}$ \\
\hline Benefit Amount & $\begin{array}{c}4.57^{* * *} \\
(0.45)\end{array}$ & $\begin{array}{c}5.09^{* * *} \\
(0.37)\end{array}$ & & \\
\hline Interview Day X Benefit Amount & $\begin{array}{c}-0.05^{* *} \\
(0.03)\end{array}$ & $\begin{array}{c}0.00 \\
(0.02)\end{array}$ & & \\
\hline Max Benefit & & & $\begin{array}{l}1.83^{*} \\
(1.07)\end{array}$ & $\begin{array}{c}6.29^{* * *} \\
(0.91)\end{array}$ \\
\hline Interview Day X Max Benefit & & & $\begin{array}{c}0.06 \\
(0.07)\end{array}$ & $\begin{array}{c}-0.10^{*} \\
(0.06)\end{array}$ \\
\hline Outcome Mean & 48.3 & 77.6 & 48.3 & 77.6 \\
\hline Total Cases & 39,696 & 39,696 & 39,696 & 39,696 \\
\hline
\end{tabular}

Source: SF-HSA. ${ }^{* * *} \mathrm{p}<0.01,{ }^{* *} \mathrm{p}<0.05,{ }^{*} \mathrm{p}<0.1$. Standard errors clustered at the case level in parentheses. All regressions are linear probability models that regress initial caseworker interview assignment day, a measure of prior year SNAP benefit receipt (either monthly benefit amount in hundreds of dollars or an indicator for receiving the maximum benefit amount), and their interaction on an indicator for recertification success (columns 1 and 3) or an indicator for ever receiving SNAP in the post-recertification year (columns 2 and 4). Analyses exclude the six cases missing benefit level information. Units are in percentage points (0100). All regressions include controls for interview assignment group (month by case language by interview type fixed effects) and demographic characteristics (household size, presence of children, and sex, age, race, and citizenship of the head of household). 
Appendix Figure 1a: Notice of Expiration of Certification (CF-377.2)

NOTICE OF ACTION

Food Stamps Termination

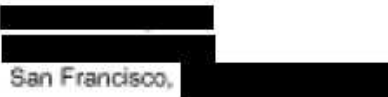

COUNTY OF SAN FRANCISCO

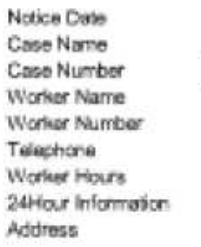

Address

Questions? Ask your Worker.

State Hearing: If you think this action is wrong, you can ask for a state hearing. The back of this page tells how. Your benefits may not be changed if you ask for a hearing before this action takes place.

1. Your CalF resh Certification period will end on $06,30,2016$.

2. If you want to keep getting your benefits without a break: you must file an application no later than the

$15 t h$ day of the last month of the certification period. You must also complete an interview with the county. and tum in any proof of income, expenses, or other information before the end of your certification period listed above.

3. If you have s one-month or two-month certification period, contact your worker for whan your application needs to be turned in.

4. You will get a seperate letter with en interview appointment date and time. Call your worker right away if you do not get the appointment letter within 10 days of this notice. Your appointment letter will tell you if you have a phone interview or if you have to come into the office for your interview. 
Appendix Figure 1b: Recertification Appointment Letter (CF-29C) STATE OF CALFONAA - HSULTH ANG HUMUN SERMCES AGENCY

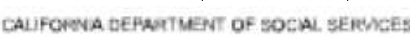

\section{CALFRESH RECERTIFICATION APPOINTMENT LETTER}

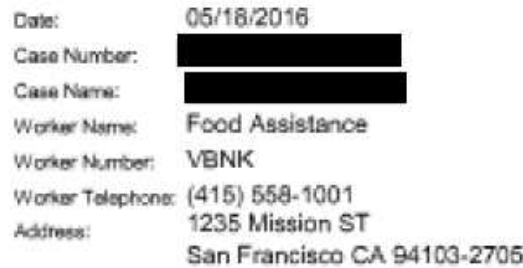

You were notifled reat your Calfresh certificeston pericot ends on 06/30/2016 sicacon You need en interview to hoep getsing CalFresh benefits. This is your sppointmant letter for your intervew.

$x$ You have a teleghone Calfresh fecertificason interview appointment. If you prefer to be interviewed in person, please eall the county at the number above for an appointment.

\begin{tabular}{|c|c|}
\hline $\begin{array}{l}\text { AFPOINTMENT DATE: } \\
\text { C601/2016 }\end{array}$ & $\begin{array}{l}\text { APPOINTMENT TIME: } \\
\text { 8:C0 AM - 12:30 PMA }\end{array}$ \\
\hline YOLIR PALONE NAIYEER: & ALTERNATIVE PLONE NLMBER: \\
\hline \multicolumn{2}{|c|}{ 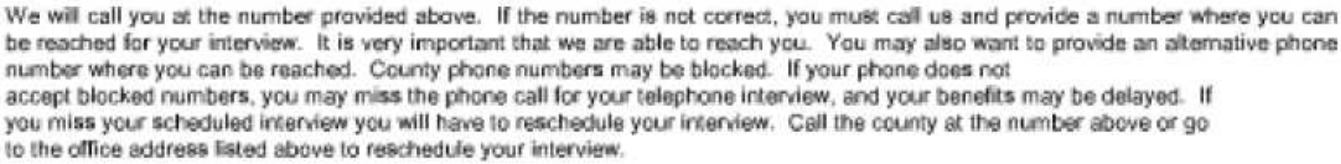 } \\
\hline
\end{tabular}

to the cifice addregs lated above to feschedule your interyien.

$\square$ You have a face-to-face Cof Fresh recertification interview appointment. APPOINTMENT DATE: APPOINTMENT TIME:

COUNTY OFFICE NAME:

COUNTY OFFICE AODRESS:

CITY

STATE:

ZIP OODE 
Appendix Figure 1c: Missed Interview Letter (CF-386)

COUNTY OF SAN FRANCISCO

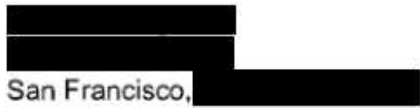

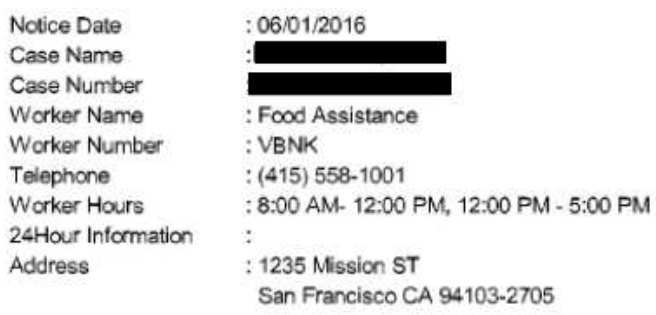

Questions? Ask your Worker.

State Hearing: If you think this action is wrong, you can ask for a hearing. The back of this page tells how. Your benefits may not be changed if you ask for a hearing before this action takes place.

You were scheduled for an interview on 06/01/2016, but you did not keep this appointment. If you still want CalFresh benefits, please contact your worker to schedule another interview.

You must complete your interview with us by 06/30/2016.

You must be interviewed in order for us to determine your eligibility for CalFresh benefits. If you do not complete an interview, you will not be able to get CalFresh benefits.

If you have any questions or want more information, please contact your worker.

Appendix Figure 2: Recertification Packet Sent Day by Interview Assignment

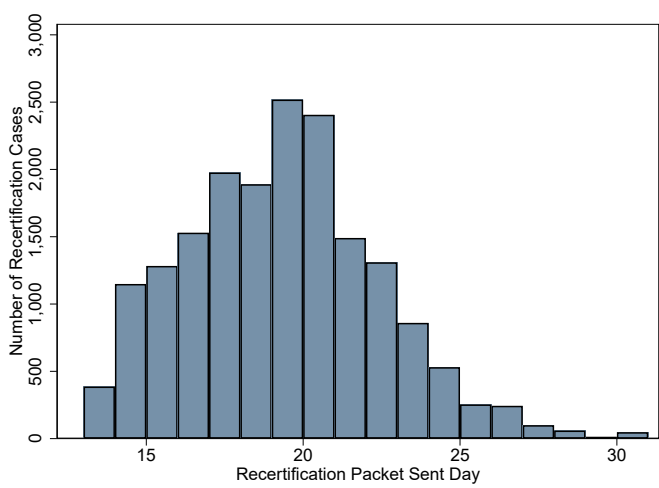

(a) Early Interview Assignments

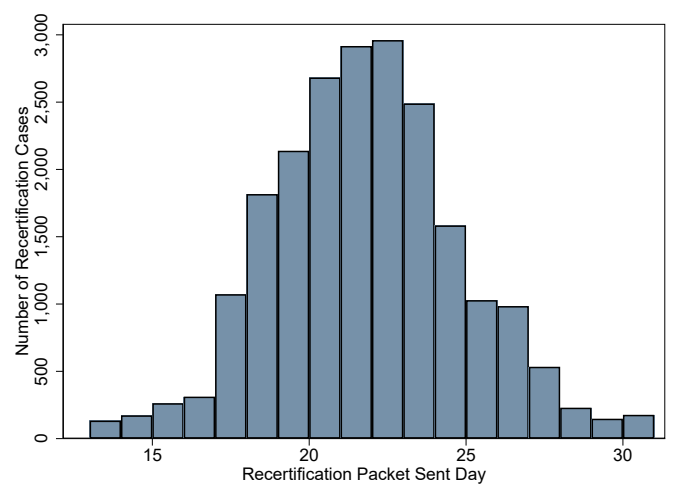

(b) Late Interview Assignments

Source: SF-HSA. This figure is a histogram of the calendar day on which a case was sent a recertification packet separately for cases with an initial interview in the first half of the recertification month (before the 14th) or in the second half of the month. All recertification packets are sent during the calendar month prior to the recertification month. 
Appendix Figure 3: Post-Recertification SNAP Participation Rate by Interview Assignment

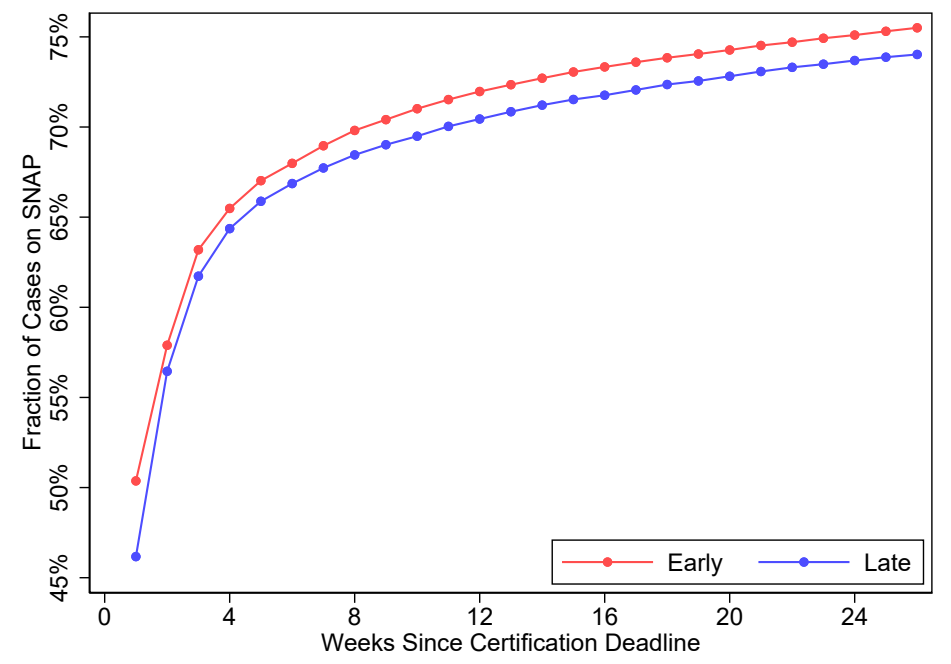

Source: SF-HSA. This figure presents the unadjusted SNAP participation rate in each week postrecertification for cases assigned to early (2nd to 13th) versus late (14th to 29th) initial interviews days of the recertification month. Cases are assumed to participate in each week following successful recertification or reapplication.

\section{Appendix Figure 4: Post-Recertification SNAP Benefit Receipt by Interview Assignment}

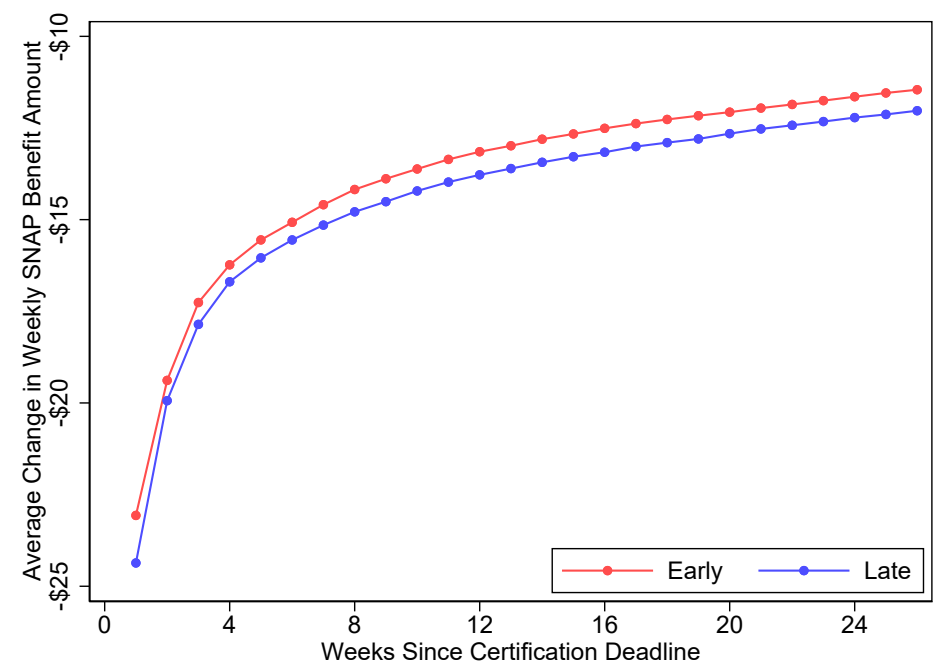

Source: SF-HSA. This figure presents the unadjusted average weekly benefit receipt as a difference between the post-recertification week and the week prior to recertification for cases assigned to early (2nd to 13th) versus late (14th to 29 th) initial interviews days of the recertification month. Cases are assumed to participate in each week following successful recertification or reapplication. Estimates of benefit levels are based on the benefit level in the recertification quarter. 